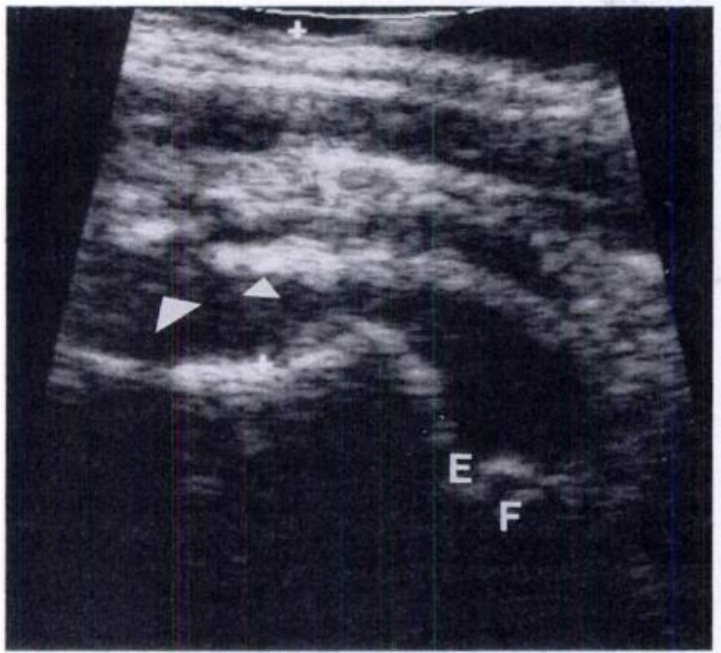

Fig. 2

Ultrasonograph of the 14-month-old boy's left hip prior to aspiration. Note the arrows demonstrating relatively little displacement of the iliofemoral ligament from the femoral neck, considering the joint contained $5 \mathrm{mls}$ of blood under pressure. $(E=$ epiphyseal plate, $F=$ femoral head).

effusion in either child (Fig. 2) but needle aspirations subsequently demonstrated intracapsular blood under pressure. Following decompression, hip movements became much freer and the hips were radiographically reduced (Fig. 1 b).

Discussion. Plain radiographs have been shown to be less accurate than ultrasound examination in the detection of hip effusion (Peck 1986); thus it has been suggested that they are redundant in the routine investigation of irritable hip. However, in our two cases tense effusions were not detected by ultrasound examinations whilst radiographic changes were clearly present. How can this come about? With a tense effusion, extrusion of the femoral head may tighten the anterior capsule across the front of the femoral neck, displacing intracapsular fluid into the acetabulum. A given volume of intracapsular fluid is therefore accommodated at lower pressure but at the expense of subluxation. In this way, with the flattening of the iliofemoral ligament against the femoral neck, the ultrasonic sign of effusion is masked. This previously unrecognised phenomenon therefore requires that subluxation is excluded by radiography before ultrasound examination can be considered reliable.

Conclusion. If a significant hip effusion is suspected on clinical grounds, both a radiograph and an ultrasound examination should be performed. Neither one in isolation can exclude an effusion.

The authors wish to thank Mr J. W. Goodfellow for permission to report case 1 .

No benefits in any form have been received or will be received from a commercial party related directly or indirectly to the subject of this article.

\section{REFERENCES}

Peck RJ. Ultrasound of the painful hip in children. Br J Radiol 1986; 59:293-4.

Wilson DJ, Green DJ, MacLamon JC. Arthrosonography of the painful hip. Clin Radiol 1984; 35:17-9.

\title{
THE TREATMENT OF HALLUX VALGUS WITH OVERRIDING SECOND TOE
}

\author{
D. CONLAN, P. J. GREGG
}

The combination of hallux valgus with an overriding second toe is a common problem for which a multitude of operations are performed. The condition has received little attention in the literature and treatment is often based on personal preference. The aim of this study, which was part of a larger prospective study of the treatment of hallux valgus, was to investigate objectively the outcome of three commonly performed operations designed to relieve the combined deformity.

Patients and methods. We studied 37 feet in 29 patients

D. Conlan, FRCS Ed, FRCS, Lecturer in Orthopaedics

P. J. Gregg, MD, FRCS, Professor of Orthopaedic Surgery

University Department of Orthopaedic Surgery, Glenfield General Hospital, Groby Road, Leicester LE3 9QP, England.

Correspondence to Mr D. Conlan.

(C) 1991 British Editorial Society of Bone and Joint Surgery 0301-620X/91/3R $16 \$ 2.00$

J Bone Joint Surg [Br] 1991 ; 73-B:519-20. who had, in addition to hallux valgus, an associated overriding of the second toe. All the patients were female. In 16 feet a Keller's procedure was combined with interphalangeal joint fusion of the second toe (group I). In a further 11 feet metatarsophalangeal fusion of the great toe and interphalangeal joint fusion of the adjacent toe was performed (group II). The remaining 10 feet underwent a Keller's procedure with proximal hemiphalangectomy of the second toe (group III). In all cases the operative technique employed depended on the surgeon's personal preference.

Patients were assessed clinically and radiologically with particular reference to the presence or absence of recurrent overriding. Statistical analysis was performed using the chi-square test with Yates 'correction for continuity' and the Fisher exact probability test.

Results. The three groups were similar in terms of age, sex distribution and the pre-operative hallux valgus angle (Table I). At presentation, all patients had symptomatic 
overriding of the second toe with subluxation of the second metatarsophalangeal joint; no frank dislocations were seen.

At review 12 to 47 months after surgery (mean 38 months), overriding had recurred in 12 feet $(32 \%)$. The recurrence rate after a Keller's operation was not significantly different from that after arthrodesis of the first metatarsophalangeal joint. In all cases of recurrent overriding, interphalangeal fusion of the second toe had been performed. By contrast, after proximal hemiphalangectomy no case of recurrent overriding was seen $(\mathrm{p}<0.02)$. special problem, which is particularly refractory to treatment. Furthermore, Cameron and Fedorkow (1982) reported that the revision rate for recurrence of symptoms following interphalangeal joint fusion of the second toe was $24 \%$ compared with only $6 \%$ for proximal hemiphalangectomy. To date, however, there have been no reports specifically investigating surgical treatment for overriding of the second toe.

As it is well established that the great toe tends to drift back into valgus following a Keller's procedure, it might be expected that this procedure would lead to recurrent overriding more frequently. This study dem-

Table I. Clinical details, treatment and outcome in 29 patients with hallux valgus and an overriding second toe

\begin{tabular}{|c|c|c|c|}
\hline \multirow[b]{2}{*}{$\begin{array}{l}\text { Hallux } \\
\text { second toe }\end{array}$} & \multicolumn{3}{|c|}{ Treatment group } \\
\hline & $\begin{array}{l}\text { I } \\
\text { Keller's } \\
\text { IPJ fusion }\end{array}$ & $\begin{array}{l}\text { II } \\
\text { MTPJ arthrodesis } \\
\text { IPJ fusion }\end{array}$ & $\begin{array}{l}\text { III } \\
\text { Keller's } \\
\text { Proximal hemiphalangectomy }\end{array}$ \\
\hline Number of patients & 15 & 6 & 8 \\
\hline Number of feet & 16 & 11 & 10 \\
\hline Mean age (range) & 64 (59 to 77$)$ & $68(49$ to 76$)$ & $69(59$ to 79$)$ \\
\hline $\begin{array}{l}\text { Mean hallux } \\
\text { valgus angle } \\
\text { Pre-operative } \\
\text { Postoperative } \\
\text { Overriding }\end{array}$ & $\begin{array}{l}43^{\circ} \\
24^{\circ} \\
\quad 7(44 \%)\end{array}$ & $\begin{array}{l}45^{\circ} \\
19^{\circ} \\
5(45 \%)\end{array}$ & $\begin{array}{l}50^{\circ} \\
23^{\circ *} \\
0 \dagger\end{array}$ \\
\hline Varus second toe & 6 & 2 & $\mathbf{0}$ \\
\hline $\begin{array}{l}\text { Neutral or valgus } \\
\text { second toe }\end{array}$ & 10 & 9 & 10 \\
\hline
\end{tabular}

The association between interphalangeal arthrodesis and recurrent deformity was accounted for by varus drift at the second metatarsophalangeal joint, which occurred in eight of the 12 cases of recurrent overriding. Following proximal hemiphalangectomy however, the second toe always lay in a neutral position or had drifted with the great toe into valgus and was thus protected against overriding ( $\mathrm{p}<0.001)$.

Pain under the second metatarsal head was present in 24 patients $(65 \%)$ pre-operatively and was relieved by surgery in all but two cases, one of whom had a proximal hemiphalangectomy and the other an interphalangeal arthrodesis. Postoperatively the second toe itself was painful in nine cases, in seven of which the pain was directly attributable to the recurrent overriding $(p<0.01)$. Dissatisfaction with the outcome of surgery was expressed by seven patients; it was due to recurrent overriding in five cases $(\mathrm{p}<0.05)$ and fibrous ankylosis in two others. Although the second toe looked short and felt floppy after hemiphalangectomy, patients did not complain about this.

Discussion. Hatcher and Smith (1978) emphasised that, severe flexion deformities of the second toe constitute a onstrates however, that recurrent overriding is not influenced by the surgical procedure performed on the great toe.

Patients who underwent interphalangeal arthrodesis of the second toe were predisposed to develop recurrent overriding, due to varus drift at the second metatarsophalangeal joint. Proximal hemiphalangectomy, on the other hand, allows the second toe to drift into valgus and thus protects against overriding.

We conclude that, for the combination of hallux valgus with an overriding second toe, surgery to the great toe can be selected according to normal clinical considerations but, to minimise recurrent overriding, a proximal hemiphalangectomy rather than fusion of the second toe should be performed.

No benefits in any form have been received or will be received from a commercial party related directly or indirectly to the subject of this article.

\section{REFERENCES}

Cameron HU, Fedorkow DM. Revision rates in forefoot surgery. Foot Ankle 1982; 3:47-9.

Hatcher RM, Smith SD. A procedure for correction of the severely subluxed second hammer toe. J Am Podiatry Assoc 1978; 68: 654-8. 